\title{
Monitoring of air radioactivity at the Jungfraujoch research station: Test of a new high volume aerosol sampler
}

\author{
Thomas Flury $^{b, 1}$, Hansruedi Völkle $e^{a, b, *}$

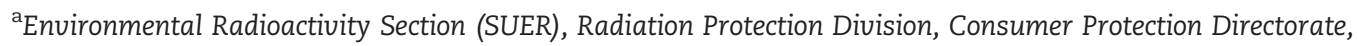 \\ Swiss Federal Office of Public Health, Chemin du Musée 3, CH-1700 Fribourg - Switzerland \\ buniversity of Fribourg, Physics Department, Chemin du Musée 3, 1700 Fribourg - Switzerland
}

Keywords: Radioactivity Aerosols Air monitoring

\begin{abstract}
The Swiss Federal Office of Public Health (SFOPH) is responsible for the surveillance of environmental radioactivity in Switzerland and for the protection of the public from ionizing and non-ionizing radiation. In order to improve the Swiss radioactivity monitoring network, a new high volume air sampler (DIGITEL DHA-80) was tested in Fribourg and at the Jungfraujoch High Altitude Research Station at $3454 \mathrm{~m}$. The filters are analyzed in the laboratory by a high purity coaxial germanium detector. In the test period natural radio nuclides and traces of ${ }^{137} \mathrm{Cs}$, due to the Chernobyl accident of April 1986, were measured and are in good agreement with values from Germany and Poland. Albeit, the main purpose of this radioactivity monitoring network is to detect rapidly any input of artificial radioactivity, it is also helpful to understand transport of natural radio nuclides in the atmosphere, as for example the cosmogenic ${ }^{7} \mathrm{Be}$ and the long-lived radon daughter ${ }^{210} \mathrm{~Pb}$. The DIGITEL sampler proved to be sufficiently reliable for aerosol radioactivity monitoring even in extreme meteorological conditions at Jungfraujoch. A detection limit for artificial ${ }^{137} \mathrm{Cs}$ of $2 \mu \mathrm{Bq} / \mathrm{m}^{3}$ is obtained.
\end{abstract}

\section{Introduction}

Switzerland started environmental monitoring of radioactivity in 1956 with the establishment of the Federal Commission for Radioactivity Surveillance (KUER) by the Swiss Federal Council. The reason was the concern about the constant rise in environmental radioactivity in the Northern Hemisphere as a consequence of the nuclear weapon tests in the 1950s and 1960s. Already in 1959, a first automatic aerosol sampling station with an on-line measurement of the gross beta radioactivity of the aerosols was installed at the Jungfraujoch research station at $3454 \mathrm{~m}$. The advantage of a sampling station at high altitude is that radioactive air masses coming from atmospheric nuclear weapon tests outside Switzerland can be detected more easily and faster than in the ground level air. So, for example, the first French nuclear weapon test of $60 \mathrm{kT}$ TNT-Equivalent, performed on February 13th 1960 in Reggane (Sahara/Algeria; Algeria was a French Department until July 5th 1962) could be easily detected at the Jungfraujoch (see Fig. 1; from Huber, 1961, p.11).

A considerable improvement was reached by replacing the gross beta-counting network by specific nuclide identification, except for Jungfraujoch where this was not possible for technical reasons. Today five high volume air samplers are in operation in Switzerland (air flow $600 \mathrm{~m}^{3} / \mathrm{h}$, type ASS-500 of the Polish manufacturer Central Laboratory for Radiological Protection Warszawa). These Polish high volume air samplers are also operated by the CTBTO Laboratory in Vienna (see Irshad et al., 2006; see also: http://www.ctbto.org/).

\footnotetext{
* Corresponding author. Sektion Überwachung der Radioaktivität, Chemin du Musée 3, CH-1700 Fribourg - Switzerland. Tel.: +41 26300 9161; fax: +4126300 9743.

E-mail addresses: thomas.flury@mw.iap.unibe.ch (T. Flury), hansruedi.voelkle@bag.admin.ch (H. Völkle).

${ }^{1}$ Present address: Institute of Applied Physics, Atmospheric Physics Group, University of Bern, Sidlerstrasse 5, 3012 Bern - Switzerland.
} 

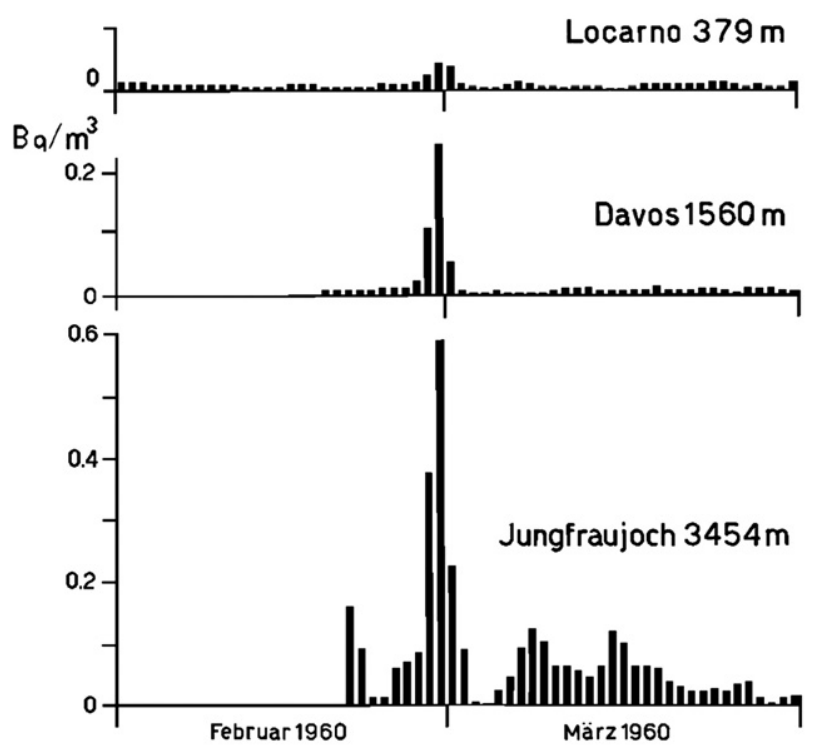

Fig. 1 - First French nuclear test explosion from February 13th 1960 in Reggane, Adrar Province, Sahara Desert (Algeria): measured gross beta activity of air collected at Locarno, Davos and Jungfraujoch (Huber, 1961).

The present work reports on the test of a new commercial high volume sampler with an air flow of up to $60 \mathrm{~m}^{3} / \mathrm{h}$ (designed originally for non-radioactive air pollution monitoring) at the Jungfraujoch High Altitude Research Station. This sampler will allow laboratory analysis of the filters by high resolution gamma spectroscopy and should provide individual data for artificial and natural radio nuclides in the air at Jungfraujoch research station. (To date only total beta radioactivity data were available at Jungfraujoch). It should improve the present Swiss radioactivity monitoring network and allow a rapid detection of any input of anthropogenic radioactivity.

\section{Sampling and measurement}

A commercial high volume aerosol sampler (DIGITEL DHA-80) developed by DIGITEL Elektronik AG CH-8604 Hegnau (Switzerland) for non-radioactive pollution monitoring was tested in Fribourg $(630 \mathrm{~m})$ and then installed at the Jungfraujoch High Altitude Research Station at $3454 \mathrm{~m}$. This sampler collects aerosol particles on $150 \mathrm{~mm}$ diameter glass fibre filters manufactured by Ederol, Binzer \& Munktell Filter GmbH, D-35088 Battenberg (Germany). The sampler is controlled remotely through an Internet connection. The air flow rate can be set between 6 and $60 \mathrm{~m}^{3} / \mathrm{h}$ and the instrument maintains a constant flow rate over the whole sampling period. Air is pumped from outside the building and is heated in order to avoid freezing of air humidity inside the tube as well as filter damage by it. The filters are changed automatically twice a week.

For the analysis by gamma spectrometry, the filters are pressed into a tablet of $6 \mathrm{~cm}$ in diameter and $3 \mathrm{~mm}$ high by means of a 15 ton hydraulic press. Normally, samples composed of the filters from 2 to 4 weeks (corresponding to approximately $16,000 \mathrm{~m}^{3}$ air at normal conditions $\mathrm{T}=288 \mathrm{~K}$, $p=1013 \mathrm{hPa}$ ) are measured by a gamma ray spectrometer using a high purity coaxial germanium detector at the Fribourg Laboratory of SUER (Radiation Protection Division of the Federal Office of Public Health). Counting time is 2 days. The activities are calculated to the middle of the sampling period.

The radio nuclides measured are the natural ${ }^{7} \mathrm{Be},{ }^{210} \mathrm{~Pb}$, ${ }^{40} \mathrm{~K}$ and traces of the artificial ${ }^{137} \mathrm{Cs}$, the latter due to resuspension of fallout from the Chernobyl reactor accident in April 26th 1986. The short-lived daughter nuclides of the uranium and thorium series are not detected for two reasons. First, the activity is very low because snow and ice at Jungfraujoch prevent the noble gas radon $\left({ }^{222} \mathrm{Rn}\right)$ from escaping into the atmosphere, and secondly, the measurement of the filters starts at least 3 days after filter change, which is enough time for those nuclides to decay significantly. ${ }^{7} \mathrm{Be}$ is a spallation product due to interactions of cosmic rays with atmospheric nitrogen and oxygen. It soon

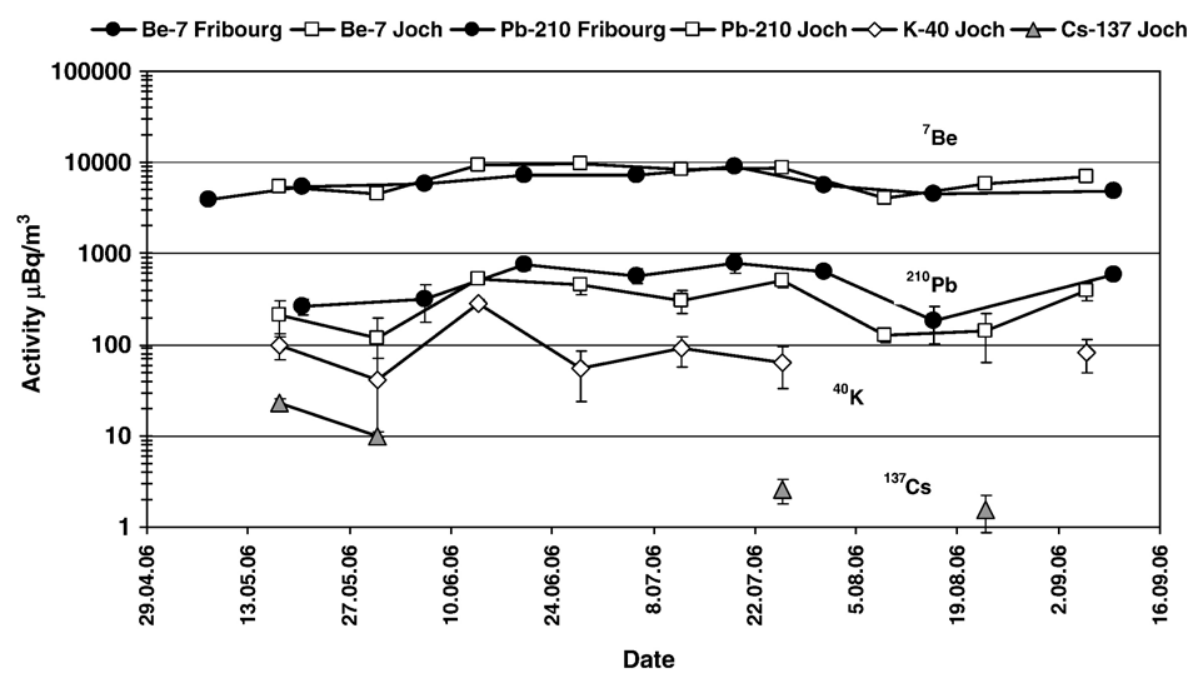

Fig. 2 - Natural $\left({ }^{7} \mathrm{Be},{ }^{40} \mathrm{~K},{ }^{210} \mathrm{~Pb}\right)$ and artificial $\left({ }^{137} \mathrm{Cs}\right)$ radionuclides measured in the air from Jungfraujoch (3454 $\left.\mathrm{m}\right)$ and comparison with the ${ }^{7} \mathrm{Be}$ and ${ }^{210} \mathrm{~Pb}$ values from Fribourg $(630 \mathrm{~m})$. 


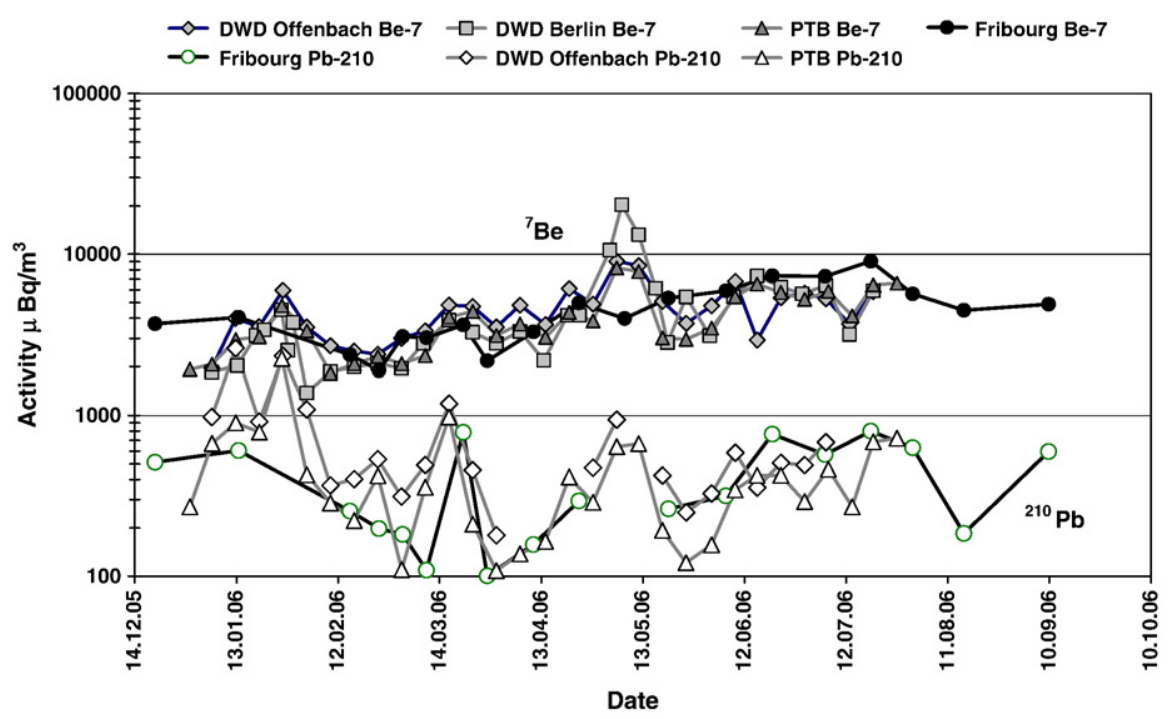

Fig. 3 - Comparison of the ${ }^{7} \mathrm{Be}$ and ${ }^{210} \mathrm{~Pb}$ concentrations in air collected at Fribourg (Oberschrot) to data from the PhysikalischTechnische Bundesanstalt (Personal communication by H. Wershofen, PTB Braunschweig - Germany, 2006) and the Deutscher Wetterdienst in Offenbach and Berlin (Personal communication by Th. Steinkopff, DWD, Offenbach - Germany, 2006).

attaches to aerosols. $67 \%$ of the production takes place in the stratosphere whilst only $33 \%$ (Zanis et al., 2003) occurs in the troposphere.

\section{Results and discussion}

From May to September 2006 natural radioisotopes ${ }^{7} \mathrm{Be}$, ${ }^{210} \mathrm{~Pb}$ and ${ }^{40} \mathrm{~K}$ were measured in all filters at Jungfraujoch. In four out of nine samples also artificial ${ }^{137} \mathrm{Cs}$ (half-life 30 years) was also detected with up to $23 \mu \mathrm{Bq} / \mathrm{m}^{3}$ on May 17th 2006 (see Fig. 2). This higher activity was confirmed by measurements of the Physikalisch-Technische Bundesanstalt in Braunschweig, Germany (personal communication by $\mathrm{H}$. Wershofen, PTB Braunschweig), the Deutscher Wetterdienst in Offenbach and Berlin (personal communication by Th. Steinkopff, DWD, Offenbach) and the Central Laboratory for Radiological Protection in Warsaw Poland (personal communication by $\mathrm{K}$. Isajenko and I. Kwiatkowska, Central Laboratory for Radiological Protection). ${ }^{137} \mathrm{Cs}$ activities were significantly higher at Jungfraujoch than in Fribourg.

The activities of ${ }^{7} \mathrm{Be}$ and ${ }^{210} \mathrm{~Pb}$ are correlated. They tend to show a common maximum in July (due to the intrusion of stratospheric air in spring for ${ }^{7} \mathrm{Be}$ and ascending air masses from the lowlands in summer for ${ }^{210} \mathrm{~Pb}$ ) and decrease towards fall in agreement with measurements from 2000 and 2001 by Tobler et al. (2001). The comparison of the results from Jungfraujoch to those of Fribourg (Fig. 2) and the results from Fribourg to those of German Laboratories (Fig. 3) shows similar temporal evolution for ${ }^{7} \mathrm{Be}$ and ${ }^{210} \mathrm{~Pb}$. Higher concentrations of ${ }^{7} \mathrm{Be}$ at Jungfraujoch match the higher concentrations of ${ }^{210} \mathrm{~Pb}$ in Fribourg. The production of ${ }^{7} \mathrm{Be}$ by cosmic ray increases with increasing altitude to reach a maximum between 17 and $20 \mathrm{~km}$. As it descends in the troposphere, a part of the short-lived ${ }^{7} \mathrm{Be}$ decays (residence time 10 to 30 days). For the ${ }^{210} \mathrm{~Pb}$ it is exactly the opposite:
${ }^{210} \mathrm{~Pb}$, as a long-lived daughter nuclide of ${ }^{222} \mathrm{Rn}$, ascends from the soil into the atmosphere. Even if ${ }^{210} \mathrm{~Pb}$ can reach appreciable altitudes, it descends by the same sedimentation and precipitation mechanisms as ${ }^{7} \mathrm{Be}$.

\section{Conclusions}

The DIGITEL aerosol sampler and its remote control by an Internet connection proved to be sufficiently reliable to work in the extreme meteorological conditions at the Jungfraujoch at $3454 \mathrm{~m}$. It will complete the actual air radioactivity network operated by the Swiss Federal Office of Public Health by a high altitude sampling station. For two-week samples a detection limit for artificial ${ }^{137} \mathrm{Cs}$ of $2 \mu \mathrm{Bq} / \mathrm{m}^{3}$ is obtained. Natural ${ }^{7} \mathrm{Be}$ and ${ }^{210} \mathrm{~Pb}$ are easily detectable and the values are in good agreement with results from German laboratories.

\section{Acknowledgments}

The authors thank Herbert Wershofen (PTB) and Thomas Steinkopff (DWD) for the permission to cite some of their results on radioactivity in the air.

\section{R E F E R E N C E S}

Huber P. 4. Bericht der Eidgenössischen Kommission zur Überwachung der Radioaktivität zuhanden des Bundesrates: 1. Oktober 1959 bis 31. Dezember 1960. Bulletin des Eidg Gesundheitsamtes vom 1961;15:11 Juli.

Irshad Hammad, Su Wei-Chung, Cheng Yung S, Medici Fausto. Testing of high-volume sampler inlet for the sampling of atmospheric radionuclides. Health Phys 2006;91(3):188-99 September. 
Zanis P, Gerasopoulos C, Priller A, Schnabel C, Stohl A, Zerefos C, et al. An estimate of the impact of stratosphere-to-troposphere transport (STT) on the lower free tropospheric ozone over the Alps using ${ }^{10} \mathrm{Be}$ and ${ }^{7} \mathrm{Be}$ measurements. J Geophys Res 2003;108:8520 NO. D12.
Tobler L, Schnabel C, Kubik PW, Schwikowski M, Gäggeler HW. Messung von atmosphärischem ${ }^{7} \mathrm{Be},{ }^{10} \mathrm{Be}$ und ${ }^{210} \mathrm{~Pb}$ an der hochalpinen Station Jungfraujoch, in Umweltradioaktivität und Strahlendosen in der Schweiz. Bundesamt für Gesundheit, Bern 2001 B. 4.5.1-4.5.5, ISBN 3-905235-40-4. 